\title{
PROPORTION OF EARLY ANTENATAL CARE BOOKING AND ASSOCIATED FACTORS IN MEKELLE CITY, PUBLIC HEALTH INSTITUTIONS, NORTHERN ETHIOPIA, 2015
}

\author{
GEBREAMLAK GIDEY ${ }^{1 *}$, DESTA ABRAHA ${ }^{2}$ \\ ${ }^{1}$ Department of Midwifery, CHS, Aksum University, Aksum, Ethiopia. ${ }^{2}$ Department of Midwifery, CHS, Adigrat University, Adigrat, Ethiopia. \\ Email: ggidey2006@ gmail.com
}

Received: 25 November 2017, Revised and Accepted: 15 March 2018

\section{ABSTRACT}

Objective: The objective of this study was to assess the proportion and associated factors for early initiation of antenatal care visit in Mekelle City, Tigray, Northern Ethiopia, 2015.

Method: An institution-based cross-sectional study was employed among 391 pregnant women's in Mekelle special zone. A systematic sampling technique was used to select study participants. Pretested structured questionnaire was used to collect the data through interview. Data were entered into EPI info version 7 and analyzed using SPSS version 20, respectively. Bivariate and multivariate logistic regression was done to see significant variables with $\mathrm{p}<0.05$ at $95 \%$ confidence interval (CI).

Result: The proportion of pregnant women who initiate early antenatal care (ANC) visit was found to be $41.1 \%$. Perceived correct time of initiation before 4 months (adjusted odds ratio [AOR] $=3.261,95 \%$ CI 1.391-7.645) and correct time told by others before 4 months with (AOR=6.617, 95\% CI $2.580,16.971$ ) were found to have statistically significant positive outcomes association with early initiation of antenatal care visit.

Conclusion: The proportion of early ANC initiation in Mekelle is lower than the World Health Organization recommendation which is <16 weeks gestation. Therefore, providing information to the community, initiation counseling, and providing health education on the benefits early ANC is crucial to improving maternal, neonatal, and child health outcomes.

Keywords: Antenatal care, Early initiation, Mekelle, Ethiopia.

(C) 2018 The Authors. Published by Innovare Academic Sciences Pvt Ltd. This is an open access article under the CC BY license (http://creativecommons. org/licenses/by/4. 0/) DOI: http://dx.doi.org/10.22159/ajpcr.2018.v11i4.23955

\section{INTRODUCTION}

The health of mothers and children remains an incomplete agenda and a global challenge. Antenatal care is defined as the routine care of pregnant women provided between the onset conception and birth [1]. Antenatal care is an opportunity to provide adequate care for prevention and management of existing and potential causes of maternal, neonatal, and child mortality and morbidity [2].

The timing of initiation of the first antenatal care booking and regular follow-up visit is paramount for ensuring optimal care and health outcomes for women and children [1,2]. In developing countries, early antenatal care (ANC) is one of the preventing mechanisms for conditions lead to life-threatening complications for the mother and her child. The World Health Organization (WHO) envisions a world where every pregnant woman and newborn receives quality care throughout the pregnancy, childbirth, and the postnatal period. Within the continuum of reproductive health care, ANC provides a platform for important health-care functions including health promotion, screening and diagnosis, and disease prevention [1-3]. The new WHO focused antenatal care model recommends that the first antenatal care visit takes place within the first 4 months of pregnancy (i.e., gestational age of $<16$ weeks) and an additional at least four visits is recommended. Crucially, ANC also provides the opportunity to communicate with and support women, families, and communities at a critical time in the course of a woman's life [3]. About 287,000 women die each year globally due to complication of pregnancy and childbirth. This magnitude indicated that every minute at least one woman dies and around $99 \%$ of maternal, newborn, and child deaths occur in developing countries. More than half of those deaths occurred in sub-Saharan Africa. In most developing countries including Ethiopia, the causes of maternal deaths are mainly due to the delay in seeking care, delay in reaching appropriate care, and delay in receiving care [4]. In developed countries and in sub-Saharan Africa, the coverage of at least one ANC is $98 \%$ and $68 \%$, respectively [5].

According to the Ethiopian Mini Demographic and Health Survey 2014 report, only $17 \%$ of women made their first ANC visit with in the recommended time, before the $4^{\text {th }}$ month of pregnancy, a $35 \%$ increase from $11 \%$ in the 2011 EDHS. However, still, $83 \%$ of pregnant mothers in Ethiopia were late for the first antenatal booking as the WHO recommendation [6].

This tragedy is much similar in many developing countries like Uganda, $17 \%$ of women's initiating ANC in the first trimester despite $47 \%$ of mothers attain at least four antenatal visits [7]. Previous studies have identified demographic factors, physical access to health facilities, parity, lack of health education, relationships with health-care providers, and misconceptions of antenatal care (ANC) as factors influencing timing of ANC booking [5,6]. Adverse pregnancy outcomes can be minimized or avoided altogether if antenatal care is received early in the pregnancy and continued through delivery. The WHO recommends that a woman without complications should have at least four antenatal visits, the first of which should take place during the first trimester [6].

Early initiation of ANC is important for prevention of maternal mortality and morbidity. Timely initiation of antennal care is critical for early identification of warning signs like high blood pressure which is called the "silent killer" [6,7] and hypertension alone is considered as the risk factor for many cardiovascular diseases during pregnancy, including new onset of diabetes. By the year 2025, the global load of hypertension is expected to increase from 1 billion to 1.56 billion, which will further worsen the conditions [8]. 
Late first antenatal care booking is a risk factor for pregnancy complication such as anemia, hypertension, hyperemesis gravid arum, gestational diabetes, congenital anomalies, preterm birth, low birth weight, sexual transmitted infection like syphilis and urinary tract infections, and acquired immunodeficiency syndrome which is an important problem for the entire world and especially for the developing countries [9-12]. Timely antenatal booking is a good opportunity to discuss with pregnant mothers on birth preparedness and complication readiness plan, warning signs of pregnancy, personal hygiene, immunization, and recommended nutrition. Evidence shows more pregnant mothers took caffeine and alcohol during their pregnancy and ingestion of caffeine during pregnancy may have some negative impacts: Decreased maternal blood supply and increased adrenaline placental concentration may lead to perinatal risk [12].

Timely the first antenatal care booking in Tigray regional state remains very low as compared with the WHO recommendation. Only $48 \%$ of pregnant mothers are booked for their first antenatal care as the standard [13], similarly, $48.2 \%$ of pregnant mothers from Adigrat town are booked their first ANC timely [14]. Previous studies reported that age at marriage, current age of the mother, means of pregnancy recognition by urine test, and perception on timing of ANC were positively associated with early initiation of ANC, and more than one parity of the mother, previous experience of service utilization, income, and unplanned pregnancy were negatively associated with early initiation of antenatal care. Those studies recommend that community-based information, education, empowering women's, and effective collaboration between antenatal care providers at all level $[10,15]$. There were few communitybased studies conducted in Tigray which depicted the magnitude of timely initiation of ANC and associated factors. Still less, there have been no facility-based studies which showed the magnitude of timely ANC booking and associated factors among urban women. Therefore, this study aimed to determine the proportion and associated factors for initiation of early ANC visit in Mekelle specialized zone public health institutions, Northern Ethiopia, 2015.

\section{METHODS}

\section{Study design, period, and area}

Institution-based cross-section study design was conducted from April 16 to May 7, 2015. The study was conducted in Mekelle special zone, northern Ethiopia, which is $780 \mathrm{~km}$ north of Addis Ababa, capital city of Ethiopia. It covers an area of 28 square $\mathrm{km}$ and the population is 286,600. Mekelle special zone has seven subcity administrations. In the city, there are four public hospital and nine public health center. The source population comprises all women attending ANC in all public health institutions of Mekelle specialized zone and study population was systematically selected pregnant woman attending ANC service in Mekelle special zone public health institutions.

\section{Sampling and sampling procedure}

Sample size was calculated using single population proportion formula with assumption of prevalence of early initiation of ANC 40.2\% [15], $95 \%$ confidence interval (CI), 5\% of margin of error, and then using correction formula and $10 \%$ of non-response rate, the calculated sample size was 391. The total number of sample size was allocated using population proportion to size to each health facility based on number of pregnant women attended in $2013 / 2014$. The study participants were interviewed during their exit after they received all the service needed. The first pregnant woman who came for the service was taken as a random start.

\section{Data collection procedures and statistical analysis}

An interviewer-administered pre-tested questionnaire was used to collect primary data, and the questionnaire was developed by reviewing different relevant literatures. The questionnaire was first prepared in English, then translated into local language which is Tigrigna by language professional and then back to English for the purpose of keeping consistency. Six diploma midwives collected the data. Pretest was done on $5 \%$ of the total sample size in Adi-Gudem health center 1 week before actual data collection. Training was given to data collectors, and supervision was done by principal investigator. Early initiation of ANC visit was the dependent variable and if a mother came for ANC service for the $1^{\text {st }}$ time before 4 months of her pregnancy, she considered as early initiation of ANC. After data were collected, each questionnaire was given code and checked visually for completeness. The data were entered into Epi-info 7 and transported to SPSS version 20 software packages for analysis. Data cleaning was performed using frequencies, sorting, listing to see missed values, and outliers and then correction was made by reviewing the original paper. Bivariate analysis was carried out first to observe the crude association between independent and outcome variables. The variables which have $p<0.05$ in bivariate analysis, not colinear were entered into multiple logistic regressions to assess the net effect by controlling confounders. Finally, statistically significant variables which fits final regression model were identified using adjusted odds ratio (AOR) with 95\% CI and $\mathrm{p}<0.05$.

\section{Ethical consideration}

Ethical clearance was obtained from Ethical Review Board of Mekelle University, College of Health Sciences, Department of Midwifery. A letter of cooperation was obtained from the Tigray Regional Health Bureau. Informed consent was obtained from each client who was informed about the objective of the study which is to contribute to set interventions and strategies to improve services. Any client who was not willing to participate in the study had the right to refuse at any time of interview. Data were collected after full informed written consent is obtained and confidentiality of the information was maintained by excluding names as identification in the questionnaire and keeping their privacy during the interview by interviewing them alone.

\section{RESULT}

\section{Sociodemographic characteristics}

Of 391 pregnant women who came for ANC follow-up, 382 pregnant women were completed the interview questionnaire and the response rate was $97.69 \%$. Respondent's age was ranges from 18 to 40 years with mean and standard deviation $26.5 \pm 5.196 .138$ (36.1\%) were in age group of 25-29 years. The ethnic composition of the respondents was Tigray $347(90.8 \%)$ followed by Amhara 28 (7.3\%) and the rest were Afar 7 (1.8\%). Orthodox Christians were 332 (86.9\%), followed by Muslim 37 (9.7\%), catholic and protestant 13 (3.4\%), respectively. Majority of the respondent were found to be married 355 (92.9\%) (Table 1).

\section{Proportion of respondent's about early initiation of antenatal care} and their reasons

The proportion of respondents who was initiated early was 157 (41.1\%). Reasons why pregnant women started early were because of they perceive it was appropriate time $86(22.5 \%)$, from their previous experience 59 (15.4\%), to confirm pregnancy $40(10.5 \%)$, health problem $8(2.1 \%)$, and unplanned pregnancy $7(1.8 \%)$. The proportions of respondents who initiate antenatal care ranged from $1^{\text {st }}$ month to 8 months and most of the respondents started at 4 months (Fig. 1).

\section{Obstetric history of respondents}

Majority of the participants were gravida two and above 257 (67.3\%) and parity one and above 243 (63.6\%). 321 (84\%) of the respondents had no history of abortion. With regard to the type or causes of abortion, $51(13.4 \%)$ of the respondents had a history of spontaneous abortion and $16(4.2 \%)$ had a history of induced abortion.

\section{Participants' previous utilization of antenatal care}

Of 243 with parity one and above, 227 (93.4\%) of respondents attended antenatal care. With regard to respondents usual practice of number of ANC visits, one visit $1(0.4 \%)$, two visits 7 (3.1\%), three visits 45 (19.8\%), four visits 154 (67.8\%), and more than four visits $20(8.8 \%) .228(59.7 \%)$ of the respondents were waiting $<2 \mathrm{~h}$ to complete checkup. 


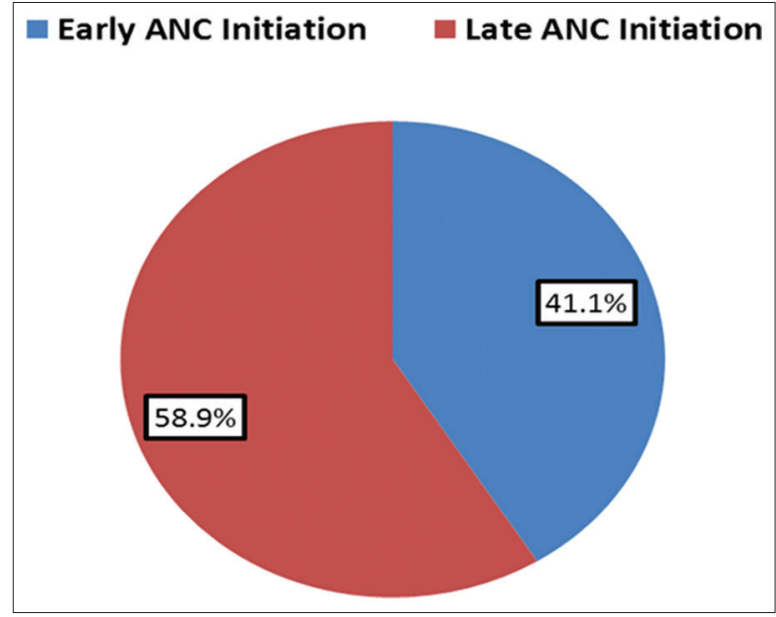

Fig. 1: Proportion of timely booking for first antenatal care among pregnant mothers $(n=382)$

\section{Participant's history about current pregnancy}

Of the total 382 participants, 205 (53.7\%) learned of their pregnancy by pregnancy test, missed period ones 115 (30.1\%), missed period twice or more $40(10.4 \%)$, and the remainder by physiological changes and illness such as nausea and vomiting. 343 (89.8\%) of the respondents said that it was planned pregnancy and out of the respondents who planned, 339 (98.8\%) was included their husband. Of those who did not plan their pregnancy, 23 (54.8\%) were not wanted after conception (Table 2).

\section{Source of information on ANC services}

Among the respondents who receive advice, 100 (47.2\%) received it from community health workers, 90 (42.5\%) from husband, followed by from friends, mother, sister, and from others. Among 138 respondents who were informed when to start ANC, $81(58.7 \%)$ of were informed that the correct time for ANC was before 4 months (Table 3).

\section{Factors associated with initiation of early ANC visit in Mekelle city}

Place of residence, age, level of education, husband's education, income, parity, perceived time of initiation, means of confirming pregnancy, and correct time told were found to be associated with early ANC initiation in the bivariate analysis. Those variables were entered once into a backward stepwise multiple logistic regression model. Finally, the model retains only those factors with statistically significant associations at $\mathrm{p}<0.05$ level. After adjustment, multivariate analysis showed that respondents who perceived before 4 months as a correct time of early ANC initiation were almost 3 times more likely to start ANC early when we compared with counterparts with AOR=3.261 and $95 \% \mathrm{CI}(1.391,7.645)$ and respondents who were told the correct time by someone before 4 months were 6.6 times more likely to start ANC early when we compared with counterparts (AOR 6.617 and 95\% CI $[2.580,16.971]$ ) (Table 4).

\section{DISCUSSION}

This study demonstrated that the proportion of participants who initiated early ANC visit was $41.1 \%$. The finding of this study is in line with the prior study conducted in Addis Ababa which was $40.2 \%$ [15]. However, the present study is greater than the Ethiopian Mini Demographic Health Survey 2014 report which was 16.6\% [6], Debre Berhan 26.2\% [10], and Southern Ethiopia, Kembata Tembaro Zone $31.4 \%$ [15]. This difference could be due to the current regional emphasis given to the focused ANC which includes the up-to-date trainings of health professionals, community health workers, mothers, and families on the importance of early ANC visit and the health education the professionals give to communities. Time gap might also be the other reason. In addition, participants might be more easily
Table 1: Sociodemographic characteristics study participants in public health institutions in Mekelle specialized zone, North Ethiopia, 2015

\begin{tabular}{|c|c|}
\hline Variable & Frequency $n=382(\%)$ \\
\hline \multicolumn{2}{|l|}{ Age group (years) } \\
\hline $15-19$ & $30(7.9)$ \\
\hline $20-24$ & $102(26.7)$ \\
\hline $25-29$ & $138(36.1)$ \\
\hline $30-34$ & $78(20.4)$ \\
\hline $35-39$ & $29(7.6)$ \\
\hline$>40$ & $5(1.3)$ \\
\hline Mean \pm SD & $(26.5 \pm 5.196)$ \\
\hline \multicolumn{2}{|l|}{ Place of residence } \\
\hline Urban & $341(89.3)$ \\
\hline Rural & $41(10.7)$ \\
\hline \multicolumn{2}{|l|}{ Educational level } \\
\hline Unable to read and write & $51(13.4)$ \\
\hline Primary school (1-8) & $96(25.1)$ \\
\hline Secondary school $(9-10)$ & $144(37.7)$ \\
\hline College diploma and above & $91(23.8)$ \\
\hline \multicolumn{2}{|l|}{ Occupation } \\
\hline Housewife & $248(64.9)$ \\
\hline Governmental employed (wedged) & $90(23.6)$ \\
\hline Private & $39(10.2)$ \\
\hline Others* & $5(1.3)$ \\
\hline \multicolumn{2}{|l|}{ Level of husband education $n=359$} \\
\hline Unable to read and write & 45 (12.5) \\
\hline Primary school (1-8) & 69 (19.2) \\
\hline Secondary school $(9-10)$ & $103(28.7)$ \\
\hline College diploma and above & $142(39.6)$ \\
\hline \multicolumn{2}{|l|}{ Transportation cost } \\
\hline Yes & $74(19.4)$ \\
\hline No & $308(80.6)$ \\
\hline \multicolumn{2}{|l|}{ Income per month } \\
\hline$<25$ USD & $19(5)$ \\
\hline 25-50 USD & $153(40)$ \\
\hline$>50$ USD & $210(55)$ \\
\hline
\end{tabular}

Others*-students, SD: Standard deviation

Table 2: Current history of the pregnancy among study participants

\begin{tabular}{ll}
\hline Variable & Frequency $\mathbf{n = 3 8 2 ~ ( \% )}$ \\
\hline $\begin{array}{l}\text { Method of knowing or confirming current } \\
\text { pregnancy }\end{array}$ & \\
$\quad$ By examination (pregnancy test) & $205(53.7)$ \\
$\quad$ Missed period & $155(40.5)$ \\
$\quad$ Physiological signs & $11(2.9)$ \\
$\quad$ Illness like nausea and vomiting & $11(2.9)$ \\
Type of pregnancy & $343(89.8)$ \\
$\quad$ Planned & $39(10.2)$ \\
$\quad$ Unplanned & \\
Pregnancy include husband (n=343) & $339(98.8)$ \\
$\quad$ Yes & $4(1.2)$ \\
$\quad$ No & \\
Unplanned pregnancy wanted by & \\
mother (n=39) & $16(41)$ \\
Yes & $23(59)$ \\
No & \\
Unplanned pregnancy wanted by & \\
husband (n=33) & $17(51.5)$ \\
Yes & $16(48.5)$ \\
No & \\
Undertake abortion (n=39) & $15(38.5)$ \\
Yes & $24(61.5)$ \\
\hline No &
\end{tabular}

accessible to different mass media. The proportion of early initiation of ANC visit in this study was lower than the study conducted in Gondar Hospital 47.4\% [1] and study conducted in New Zealand 
$73.4 \%$ [16]. The possible difference may be due to sociodemographic characteristics difference between Ethiopia and New Zealand. However, on the contrary, the result of this study was significantly higher than the study conducted in southwestern Nigeria $17.4 \%$ [17]. This might

Table 3: Source of information of the study participants on ANC services $(n=382)$

\begin{tabular}{ll}
\hline Variable & Frequency (\%) \\
\hline Perceived time of initiation & $177(46.3)$ \\
$\quad$ < months & $205(53.7)$ \\
At or after 4 months & $212(55.5)$ \\
Advised by someone & $170(44.5)$ \\
$\quad$ Yes & \\
No & $100(47.2)$ \\
Who advised you? (n=212) & $90(42.5)$ \\
Community health workers & $8(3.8)$ \\
Husband & $7(3.3)$ \\
Friends & $4(1.9)$ \\
Mother & $3(1.4)$ \\
Sister & $138(65.1)$ \\
Others* & $74(34.9)$ \\
Informed you when to start? (n=212) & \\
Yes & \\
No & \\
Correct time received from their advisors & $57(58.7)$ \\
(n=138) & \\
Before 4 months & \\
At or after months &
\end{tabular}

be due to the time gap between the two studies and sociodemographic characteristics difference between Ethiopia and Nigeria. The odds of having pregnant women's perception on correct time before 4 months were significantly associated with early initiation of antenatal care with AOR $=3.261,95 \%$ CI (1.391-7.645). Pregnant women's perceived before 4 months were the correct time to initiate early ANC were 3 times more likely to initiate with the recommended time when we compared with their counterparts.

This finding is agreed with the study done in Adigrat town [14], study done in Debre Birhan, Ethiopia [11], and a study from Addis Ababa. This entails that respondents who were informed to book within 12 weeks of gestation were more likely to book within the recommended time [15]. Furthermore, it is in line with the study conducted in Nigeria which suggested that pregnant mothers who have knowledge were booked timely [18].

The possible reasons could be that they had a good knowledge about the importance of early initiation antenatal care. Additional reason could be due to accessible to different mass media and information on the correct time of initiation. The result of this study showed that the odds of having pregnant women's who were informed the correct time to start early ANC by someone were 6.6 times more likely to initiate antenatal care early when we compared with pregnant women's who did not inform the correct time of initiation for early ANC by someone with $\mathrm{AOR}=6.617$, 95\% CI (2.580-16.971). This finding is also agreed with similar studies from Addis Ababa [15] qualitative data which confirms that service providers advise pregnant women to come for the service follow-up after they complete 4 months when they booked in the first trimester. In this study, it was found that respondents who

Table 4: The bivariate and multiple logistic regression results on factors associated with initiation of early ANC visit in public health institutions at Mekelle special zone, North Ethiopia

\begin{tabular}{|c|c|c|c|c|}
\hline \multirow[t]{2}{*}{ Variable } & \multicolumn{2}{|c|}{ Time of initiation } & \multirow[t]{2}{*}{ Crude OR (95\% CI) } & \multirow[t]{2}{*}{ Adjust OR (95\% CI) } \\
\hline & Early (\%) & Late (\%) & & \\
\hline \multicolumn{5}{|l|}{ Age group (years) } \\
\hline$<25$ & $86(52.1)$ & $79(47.9)$ & $1.637(1.084,2.473) *$ & $1134(0.432,2.975)$ \\
\hline$>25$ & $139(64.1)$ & $78(35.9)$ & 1 & 1 \\
\hline \multicolumn{5}{|l|}{ Place of residence } \\
\hline Urban & $147(43.1)$ & $194(56.9)$ & 1 & 1 \\
\hline Rural & $10(24.4)$ & $31(75.6)$ & $0.426(0.202,0.896)^{*}$ & $0.420(0.133,1.389)$ \\
\hline \multicolumn{5}{|l|}{ Educational level } \\
\hline Unable to read and write & $13(25.5)$ & $38(74.5)$ & 1 & 1 \\
\hline Primary school & $35(36.5)$ & $61(63.5)$ & $1.677(0.789,3.567)$ & $0.818(0.116,5.790)$ \\
\hline Secondary school & $67(46.5)$ & $77(53.5)$ & $2.543(1.251,5.172)^{*}$ & $1.013(0.202,5.086)$ \\
\hline College diploma and above & $42(46.2)$ & $49(53.8)$ & $2.505(1.180,5.318)^{*}$ & $1.741(0.439,6.909)$ \\
\hline \multicolumn{5}{|l|}{ Husband education } \\
\hline Unable to read and write & $11(24.4)$ & $34(75.6)$ & 1 & 1 \\
\hline Primary school & $25(36.2)$ & $44(63.8)$ & $1.756(0.759,4.062)$ & $0.792(0.183,3.422)$ \\
\hline Secondary school & $45(43.7)$ & $58(56.3)$ & $2.398(1.096,5.250)^{*}$ & $0.4560(0.109,1.909)$ \\
\hline \multicolumn{5}{|l|}{ Income per month } \\
\hline$<500$ birr & $4(21.1)$ & $15(78.9)$ & $0.293(0.094,0.913)^{*}$ & $0.290(0.024,3.471)$ \\
\hline 500-1000 birr & $53(34.6)$ & $100(65.4)$ & $0.583(0.380,0.896)^{*}$ & $0.692(0.242,1.980)$ \\
\hline$>1000$ birr & $100(47.6)$ & $110(52.4)$ & 1 & 1 \\
\hline \multicolumn{5}{|l|}{ Parity } \\
\hline Zero parity & $69(49.3)$ & $70(50.3)$ & $1.692(1.108,2.584)^{*}$ & 1 \\
\hline$>1$ parity & $89(36.5)$ & $155(63.5)$ & 1 & $1.133(0.345,3.717)$ \\
\hline \multicolumn{5}{|l|}{ Perceived time of initiation } \\
\hline$<4$ months & $125(70.6)$ & $52(29.4)$ & $12.996(7.907,21.359)^{*}$ & $3.261(1.391,7.645)^{*}$ \\
\hline$>4$ months & $32(15.6)$ & $173(84.4)$ & 1 & \\
\hline \multicolumn{5}{|l|}{ Confirming pregnancy } \\
\hline Missed period & $58(32.8)$ & $119(67.2)$ & $0.522(0.344,0.792)^{*}$ & $0.594(0.250,1.415)$ \\
\hline Urine test & $99(48.3)$ & $106(51.7)$ & 1 & 1 \\
\hline \multicolumn{5}{|l|}{ Correct time told } \\
\hline$<4$ months & $51(63)$ & $30(37)$ & $10.412(4.350,24.926)^{*}$ & $6.617(2.580,16.971)^{*}$ \\
\hline$>4$ months & $8(14)$ & $49(86)$ & 1 & 1 \\
\hline
\end{tabular}


were informed to book within 12 weeks of gestation were more likely to book within the recommended time. This study result is comparable with the study conducted in Nigeria which demonstrates that pregnant women who were advised by physicians were booked timely [19]. This suggested that proper counseling information, communication, and advice on pattern of ANC utilization from service providers are important to book timely.

\section{CONCLUSION}

The proportion of early ANC initiation as per the WHO recommended time is found to be low. Perception of mothers on correct time of initiation for antenatal care (before 4 months) and receiving adequate information on the recommended time for antenatal care booking remains the determinant factors of early initiation of antenatal care. Therefore, providing information to the community, integrated counseling, and health education about early initiation of antenatal care could be crucial to tackle such kind of the problem.

\section{ACKNOWLEDGMENT}

We would like to thank Adigrat University, College of Health Sciences, and Department of Midwifery, for funding of this research. Last but not least, we would like to thank all study participants and data collectors for their contribution in success of our work.

\section{AUTHORS' CONTRIBUTIONS}

GG and DA contributed to the initiation of the study, design, participating in organizing the data collection process and analysis of the result. GG and DA involved in the reanalysis of the data, writing of the manuscript. All authors read and approved the final manuscript.

\section{CONFLICT OF INTERESTS}

The authors declare that there is no conflict of interests regarding the publication of this paper.

\section{REFERENCES}

1. Belayneh T, Adefris M, Andargie G. Previous early antenatal service utilization improves timely booking: Cross-sectional study at university of Gondar hospital, Northwest Ethiopia. J Pregnancy 2014;1:1-8.

2. Exavery A, Kanté AM, Hingora A, Mbaruku G, Pemba S, Phillips JF. How mistimed and unwanted pregnancies affect timing of antenatal care initiation in three districts in Tanzania. BMC Pregnancy Childbirth 2013; $13: 35-46$

3. Brown CA, Khan K, Lilford R, Sohani SB, Mukhwana W. Antenatal care and perinatal outcomes in Kwale district, Kenya. BMC Pregnancy Childbirth 2008;8:2-13.

4. Chemir F, Alemseged F, Workneh D. Satisfaction with focused antenatal care service and associated factors among pregnant women attending focused antenatal care at health centers in Jimma town, Jimma zone, South West Ethiopia; A facility based cross-sectional study triangulated with qualitative study. BMC Res Notes 2014;7:164-72.

5. Fesseha G, Etana B, Haileslassie K, Zemene A. Perceived quality of antenatal care service by pregnant women in public and private health facilities in Northern Ethiopia. Am J Health Res 2014;2:146-51.

6. Central Statistical Agency. Ministry of Health, and Addis Ababa. Ethiopia: Ethiopia Mini Demographic Health Survey; 2014. p. 39-44.

7. Bbaale E. Factors influencing timing and frequency of antenatal care in Uganda. Aust Med J 2011;4:431-8.

8. Vikas JH, Ag BK, Partha RO, Vipin SA. Prevalence and risk factors of essential hypertention and new onset of diabetes in essential hypertenstion in rural population of Haryana. Int $\mathbf{J}$ Pharm Pharm Sci 2018;10:142-8.

9. Gudayu TW, Woldeyohannes SM, Abdo AA. Timing and factors associated with first antenatal care booking among pregnant mothers in Gondar Town; North West Ethiopia. BMC Pregnancy Childbirth 2014;14:287-94.

10. Birmeta K, Dibaba Y, Woldeyohannes D. Determinants of maternal health care utilization in Holeta town, central Ethiopia. BMC Health Services Res 2013;13:256-66.

11. Zegeye AM, Bitew BD, Koye DN. Prevalence and determinants of early antenatal care visit among pregnant women attending antenatal care in Debre Berhan Health Institutions, Central Ethiopia. Afr J Reprod Health 2013;17:130-6.

12. Muaed MJ. Evaluation of caffeine consumption and effect during pregnancy among women in the Uae. Int $J$ Pharm Pharm Sci 2016;8:101-3.

13. Berhe KK, Welearegay HG, Abera GB, Kahsay HB, Kahsay AB. Assessment of antenatal care utilization and its associated factors among 15 to 49 years of age women in Ayder Kebelle, Mekelle City 2012/2013; A cross sectional study. Open J Adv Drug Deliv 2014;2:62-75.

14. Lerebo W, Kidanu A, Tsadik M. Magnitude and associated factors of late booking for antenatal care in public health centers of Adigrat town, Tigray. Ethiop Clin Mother Child Health 2015;12:171-8.

15. Tariku A, Melkamu Y, Kebede Z. Previous utilization of service does not improve timely booking in antenatal care: Cross sectional study on timing of antenatal care booking at public health facilities in Addis Ababa. Ethiop J Health Dev 2010;24:226-33.

16. Low P, Paterson J, Wouldes T, Carter S, Williams M, Percival T. Factors affecting antenatal care attendance by mothers of Pacific infants living in New Zealand. N Z Med J 2005;118:1-10.

17. Adekanle D, Isawumi A. Late antenatal care booking and its predictors among pregnant women in South Western Nigeria. Online J Health Allied Sci 2008;7:4-10.

18. Ndidi EP, Oseremen IG. Reasons given by pregnant women for late initiation of antenatal care in the Niger delta Nigeria. Ghana Med J 2010;44:47-51.

19. Okunlola MA, Ayinda OA, Owonikoko KM, Omigbodum AO. Factors influencing gestational age at ANC booking at the university college hospital, Ibadan, Nigeria. J Obstetr Gynecol 2006;26:195-7. 